\title{
THE
}

\section{Air-soil diffusive exchange of PAHs in an urban park of Shanghai based on polyethylene passive sampling: Vertical distribution, vegetation influence and diffusive flux}

Ying Liu

Shuya Xie

Lirong Zheng

Tongtong Li

Yajie Sun

Follow this and additional works at: https://digitalcommons.uri.edu/gsofacpubs

The University of Rhode Island Faculty have made this article openly available.

Please let us know how Open Access to this research benefits you.

This is a pre-publication author manuscript of the final, published article.

Terms of Use

This article is made available under the terms and conditions applicable towards Open Access

Policy Articles, as set forth in our Terms of Use.

\section{Citation/Publisher Attribution}

Liu, Ying; Xie, Shuya; Zheng, Lirong; Li, Tongtong; Sun, Yajie; Ma, Limin; Lin, Zhifen; Grathwohl, Peter; Lohmann, Rainer. Air-soil Diffusive Exchange of PAHs in an Urban Park of Shanghai Based on Polyethylene Passive Sampling: Vertical Distribution, Vegetation Influence and Diffusive Flux. Sci Tot Environ 2019, 689, 734-742. doi: 10.1016/j.scitotenv.2019.06.500

Available at: https://doi.org/10.1016/j.scitotenv.2019.06.500

This Article is brought to you for free and open access by the Graduate School of Oceanography at DigitalCommons@URI. It has been accepted for inclusion in Graduate School of Oceanography Faculty Publications by an authorized administrator of DigitalCommons@URI. For more information, please contact digitalcommons-group@uri.edu. 


\section{Authors}

Ying Liu, Shuya Xie, Lirong Zheng, Tongtong Li, Yajie Sun, Limin Ma, Zhifen Lin, Peter Grathwohl, and Rainer Lohmann 


\section{Air-soil Diffusive Exchange of PAHs in an Urban Park of}

2 Shanghai Based on Polyethylene Passive Sampling:

3 Vertical Distribution, Vegetation Influence and Diffusive

4 Flux

5

YING LIU ${ }^{\dagger, \neq, *}$, SHUYA XIE ${ }^{\dagger, \neq}$, LIRONG ZHENG ${ }^{, \dagger}$, TONGTONG LI ${ }^{\dagger}$, YAJIE

SUN $^{\dagger}$, LIMIN MA ${ }^{\dagger}$, ZHIFEN LIN", PETER GRATHWOHL ${ }^{\S}$, RAINER

8 LOHMANN $I$

9

+ State Key Laboratory of Pollution Control and Resource Reuse, College of Environmental

11 Science and Engineering, Tongji University, 1239 Siping Road, Shanghai 200092, China

12 ₹China Meteorological Administration Key Laboratory of Cities' Mitigation and Adaptation to

13 Climate Change (Shanghai Meteorological Bureau), IESD, Tongji University, Shanghai

14 200092, China

15 \$Shanghai Shangde Experimental School, 1688 Xiuyan Road, Shanghai 200092, China

16 \#Shanghai Key Lab of Chemical Assessment and Sustainability, College of Environmental

17 Science and Engineering, Tongji University, 1239 Siping Road, Shanghai 200092, China

18 ¿enter for Applied Geoscience, University of Tübingen, Hölderlinstrasse 12, 72074 Tübingen,

19 Germany

20 "I Graduate School of Oceanography, University of Rhode Island, Narragansett, Rhode Island

21 02882-1197, United States.

22

23

24

$25 *$ To whom correspondence should be addressed

26 E-mail address: liu_ying@tongji.edu.cn (Y. Liu)

27

28 

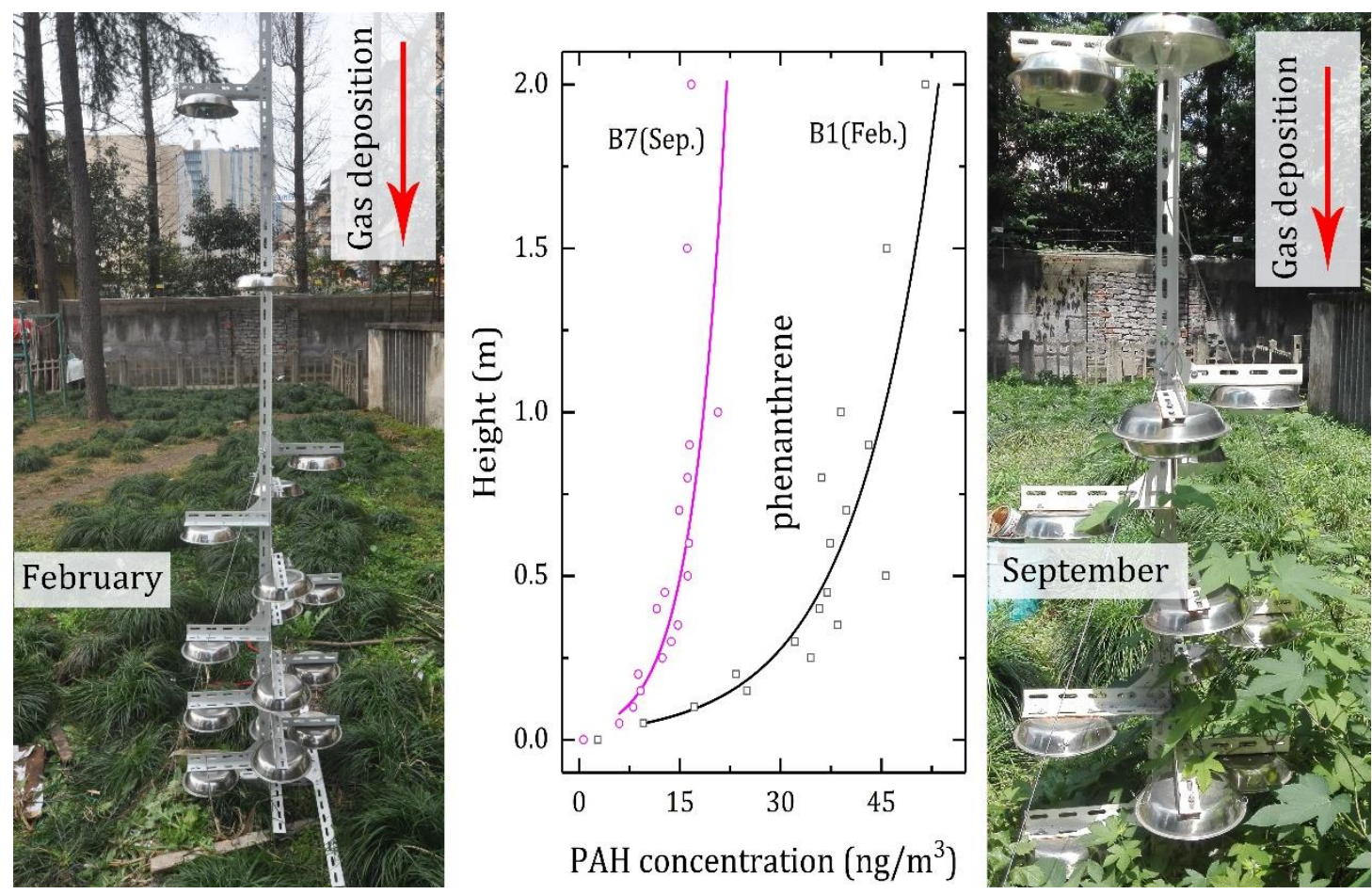

32 


\section{HIGHLIGHTS}

34 - Gas deposition for phenanthrene and volatilization for benzo[b]fluoranthene.

35 - Impact of vegetation on vertical pattern of PAHs was observed only in growing season.

36 - Vertical eddy diffusivity in air was calculated by local micrometeorological conditions.

37 Diffusive flux of gaseous PAHs in air-soil exchange was compared from two approaches.

38

39 
ABSTRACT:

41 Compared with dry and wet deposition rates, air-soil exchange fluxes cannot be directly measured experimentally. Polyethylene passive sampling was applied to assess transport directions and to measure concentration gradients in order to calculate diffusive fluxes of polycyclic aromatic hydrocarbons (PAHs) across the air-soil interface in an urban park of Shanghai, China. Seven campaigns with high spatial resolution sampling at 18 heights between 0 and $200 \mathrm{~cm}$ above the ground were conducted in 2017 - 2018. Air-to-soil deposition was observed, e.g. for phenanthrene, and soil-to-air volatilization for high molecular weight compounds, such as benzo[b]fluoranthene. Significant linear correlations between gaseous PAH concentration and log-transformed height were observed.

51 Influence of vegetation on vertical concentration gradients of gaseous PAHs was

52 insignificant in most cases except during the growing season. Local

53 micrometeorological conditions resulted in a directional eddy diffusion in air and

54 then influenced vertical diffusion of gaseous PAHs. Furthermore, the vertical

55 eddy diffusivity was estimated as a function of distance to the air-soil surface.

56 Air-soil exchange fluxes based on the Mackay's fugacity approach were calculated

57 and confirmed by diffusive fluxes within air layer based on vertical concentration

58 gradient of PAHs and eddy/molecular diffusion. Polyethylene passive sampling

59 technology provides a useful tool to investigate air-soil exchange process.

60

61 KEYWORDS:

62 LDPE, gas exchange, eddy diffusion, molecular diffusion, fugacity, uncertainty 63 analysis. 


\section{INTRODUCTION}

Polycyclic aromatic hydrocarbons (PAHs) are a ubiquitous class of semi-volatile organic pollutants mainly originating from the combustion of organic matter and fuels (Liu et al., 2015), and are widespread all over the world (Casal et al., 2018). Consequently, the earth surface (e.g. soil and vegetation) becomes a critical sink of these hydrophobic pollutants via atmospheric deposition and direct application e.g. by sewage sludge (Feng et al., 2017; Zheng et al., 2015). After primary pollutant sources were reduced or eliminated in air, soils may become secondary sources of accumulated semi-volatile organic compounds depending on air-surface exchange rates (Bao et al., 2015; Degrendele et al., 2016).

To assess air-soil exchange, many studies quantified gradients in air and soil fugacities based on model predictions or field measurements. The latter include active air sampling (e.g. low-volume air samplers) (Degrendele et al., 2016; KurtKarakus et al., 2006; Tasdemir et al., 2012; Wang et al., 2015) and more recently passive sampling technologies to measure the air fugacity based on polyurethane foam, low-density polyethylene (LDPE) and other materials (Donald and Anderson, 2017; Dumanoglu et al., 2017; Wang et al., 2017; Zhang et al., 2011). Also, concentrations measured in soil samples were converted to fugacities based on air-soil partitioning coefficients and ambient temperatures (Cetin et al., 2017a; Cetin et al., 2019; Qu et al., 2019; Tasdemir et al., 2012; Wang et al., 2017; Zhang et al., 2011). However, large uncertainties exit in estimating air-soil partitioning coefficients and because of soil heterogeneity, e.g. during soil sampling vertical concentration gradients are disturbed leading to misinterpretation on soil fugacity (Ali et al., 2015; Davie-Martin et al., 2015; 
Donald and Anderson, 2017). Alternative in situ technologies have been developed to directly monitor the soil air, namely the gas phase in soil pores. For example, active fugacity samplers were designed to sample the air close to the soil surface (Cabrerizo et al., 2009; Degrendele et al., 2016; Wang et al., 2015). Donald and Anderson (2017) designed a soil air fugacity sampler based on passive sampling using polyethylene. In addition to assessing the fugacity gradient between soil and air phases, vertical concentration gradients in air can serve as an alternative indicator and reflect the driving force of the air-soil exchange. For example, Kurt-Karakus et al. (2006) mounted active air samplers at the heights of 5, 20, 72, and $200 \mathrm{~cm}$ above ground. Lammel et al. (2011) also actively collected air samples from 1.1 and $2.3 \mathrm{~m}$ above the soil surface. To not disturb the atmospheric concentration gradients caused by active sampling, Zhang et al. (2011) and Wang et al. (2017) deployed PUF air passive samplers at various heights above the surface.

Many studies focused only on assessing transport direction of air-soil diffusive exchange based on fugacity ratio of air and soil (Cetin et al., 2017a; Cetin et al., 2017b; Degrendele et al., 2016; Tian et al., 2016; Wang et al., 2015; Zhu et al., 2017). However, only in few studies exchange fluxes were calculated based on fugacity gradients between soil and air, following the Mackay fugacity approach (Koblizkova et al., 2009; Pokhrel et al., 2018; Tasdemir et al., 2012; Wang et al., 2017; Zhang et al., 2011) or Fick's law of diffusion (Donald and Anderson, 2017). If the influence of vegetation on air-soil is negligible, the diffusive flux within air layer overlying the soil surface would be equal to the air-soil diffusive exchange rates. This prompted us to deploy more passive samplers with high spatial resolution in the topsoil and air at various heights above ground, in order to 
estimate and compare the diffusive fluxes from the two methods. Low density polyethylene (LDPE) passive samplers were placed in heights of $5-200 \mathrm{~cm}$ above the soil surface during 2017 - 2018. The objectives of this study were to (a) investigate vertical distribution of gaseous PAHs within air phase and determine their transport direction in air-soil exchange process, (b) assess influence of vegetation on the vertical distribution of gaseous PAHs, (c) quantify eddy diffusivities and estimate diffusive fluxes of gaseous PAHs at different heights above the surface based on local micrometeorological conditions, and (d) compare diffusive fluxes within air phase and in the air-soil exchange interface.

\section{MATERIALS AND METHODS}

\subsection{Study site.}

The monitoring site was located in a green space in the city center of Shanghai, China, $\sim 60$ meters from the Inner-ring Elevated Road (see Figure S1). This field was selected to investigate the main atmospheric transport pathway for anthropogenic emissions from the densely populated and highly urbanized area in the Eastern China. The green space is a typical receptor of urban pollutant emissions, in particular traffic-related emissions. During sampling, local temperature ranged from $3-40^{\circ} \mathrm{C}$ and average wind speed was $<1.5 \mathrm{~m} \mathrm{~s}^{-1}$ with the maximum of $5.5 \mathrm{~m} \mathrm{~s}^{-1}$.

\subsection{Samplers and sampling design.}

Commercial $51 \mu$ m-thick low-density polyethylene (LDPE) was cut into strips of $40 \mathrm{~cm} \times 10 \mathrm{~cm}$. The strips were cleaned and spiked with performance reference compounds (PRCs, more details in the SI) (Liu et al., 2016). The sharpest 
139

variations in meteorological variables with height occur within the surface roughness layer ( $<100 \mathrm{~cm}$ above ground in this study). Air samplers were deployed as an array along a gradient of 17 heights from $5 \mathrm{~cm}$ to $200 \mathrm{~cm}$ above ground, and were fixed non-uniformly at 5, 10, 15, 20, 25, 30, 35, 40, 45, 50, 60, 70, 80, 90, 100, 150, and $200 \mathrm{~cm}$ above ground (see Figure S2). To avoid individual samplers blocking each other, they were sequentially distributed in four directions. Meanwhile, three soil samplers $(50 \mathrm{~cm} \times 13 \mathrm{~cm} \times 2 \mathrm{~cm})$ were deployed immediately adjacent to the air samplers $\left(<1 \mathrm{~m}^{2}\right)$. The soil sampler (a LDPE strip was protected by a metal grid) was vertically inserted into topsoil ( $<15 \mathrm{~cm}$ deep), and stainless steel boxes were placed over the LDPE passive samplers. Seven sampling campaigns of 2 - 8 weeks were performed from Match of 2017 to September of 2018. Detailed information on air/soil samplers and temporal coverage is provided in the SI (see Figures S2-S3 and Table S1).

\subsection{Sample analysis and QA/AC.}

After sampling, LDPE samples were wiped clean by pure water and hexane to remove the particles and soil dust absorbed on the surface of LDPE strips, and analyzed for PAH concentrations. The LDPE samples were treated according to a method published previously (Liu et al., 2016). Briefly, all LDPE sheets were spiked with surrogate standards (five deuterated PAHs) to assess recovery, and then extracted overnight in dichloromethane and hexane, sequentially. After extracts were concentrated, an injection standard (deuterated fluorene) was added before GCMS analysis. No additional sample cleanup was performed for air samples, while soil samples were passed through a silica gel and sodium sulfate column for cleanup. 16 US EPA PAHs were quantified using an Agilent GC 7890A 
with a HP-5 MS fused silica capillary column $(30 \mathrm{~m} \times 0.25 \mathrm{~mm}$ i.d., $0.25 \mu \mathrm{m}$ film thickness) equipped with an Agilent 5975C MSD in EI+ selected ion monitoring (SIM) mode. PAH concentrations in LDPE samples were corrected for surrogate standard recoveries and blank-subtracted using field blanks in the same sampling batch. PAH concentrations in field blanks were $<10 \%$ of measured concentrations in samples for 3 - 4 rings PAHs, and $<20 \%$ for 5 - 6 rings PAHs, except naphthalene (30\%) and dibenz [a,h] anthracene (47\%) (see Table S2). PRC concentrations in field and lab blanks from each batch were used to quantify initial concentrations of PRCs in deployed samples. Measured concentrations in LDPE were used to calculate (equivalent) gaseous concentrations of PAHs in air (or soil) based on LDPE-air partition coefficients corrected to ambient temperature (Liu et al., 2016; McDonough et al., 2014). The calculation is based on the assumption that the uptake rate of target PAHs from ambient environment to the LDPE sheet is equal to the loss rate of PRCs from the LDPE sheet (Booij and Smedes, 2010). Equilibrium percentages of target PAHs were calculated from the quantities of PRCs remaining in each sample. More analytical details and calculations are shown in the Supporting Information (see Tables S2 and S3). Procedural blanks and field blanks were performed during each campaign to assess the potential contamination for quality assurance. Limits of detection of PAHs were $<1 \mathrm{ng} \mathrm{m}^{-3}$ in air and soil air except naphthalene and acenaphthene. Average recoveries of surrogate standards were 45 - $81 \%$ and average relative standard deviation percentages of target PAHs were 10 - 25\%. Sampling rates were $16 \mathrm{~m}^{3}$ day-1 in air and $4.7 \mathrm{~m}^{3}$ day $^{-1}$ in soil, respectively. More information on quality assurance and quality control is in the Supporting Information (Tables S1-2 and S4). 


\subsection{Air-soil diffusive exchange flux of PAHs.}

191 The mass flux $\left(F_{\mathrm{a} / \mathrm{s}}\right.$, in $\mathrm{ng} \mathrm{m}^{-2}$ day $\left.^{-1}\right)$ is driven by the difference in target's chemical

192 activity between air and soil matrixes, and the Mackay's surface soil fugacity

193 approach was employed for the calculation (Mackay, 2001), see Equation 1.

$195 \quad F_{a / s}=\frac{\left(C_{p e, a}-C_{p e, s}\right)}{K_{P E-a}} \times v_{a / s}$

197 where $C_{\mathrm{pe}, \mathrm{a}}$ and $C_{\mathrm{pe}, \mathrm{s}}$ are the equilibrium concentrations of PAHs in PE matrix 198 deployed in air and soil, respectively, and $K_{\text {PE-a }}$ is the air temperature-corrected 199 PE-air partition coefficient. Details on estimating overall mass transfer velocity in 200 air-soil diffusive exchange of PAHs $\left(\mathrm{V}_{\mathrm{a}} \mathrm{s}\right.$, in $\mathrm{m}$ day $\left.^{-1}\right)$ from the volume fractions of 201 soil water and soil air are provided in the Supporting Information, and the 202 calculated $v_{\mathrm{a} / \mathrm{s}}$ and $F_{\mathrm{a} / \mathrm{s}}$ values are presented in Table S5.

\subsection{Vertical diffusive flux of PAHs within the air layer.}

205 Both random molecular motion and turbulence promote mixing within the air 206 layer. The vertical diffusive flux ( $F_{\text {Dual, }}$ in $\mathrm{ng} \mathrm{m}^{-2}$ day $\left.^{-1}\right)$ consists of two parts, 207 namely the vertical eddy diffusive flux and the molecular diffusive flux $\left(F_{\text {Eddy }}\right.$ and

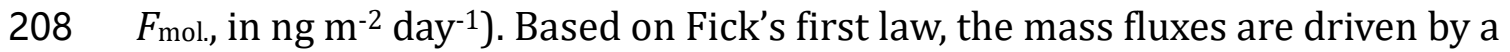
209 vertical gradient of PAH concentrations $(\mathrm{dC} / \mathrm{dH})$, and related to molecular 210 diffusivity $\left(D_{\mathrm{A}}\right.$, in $\mathrm{m}^{2}$ day $\left.^{-1}\right)$ and vertical eddy diffusivity $\left(E_{\mathrm{z}}\right.$, in $\mathrm{m}^{2}$ day $\left.^{-1}\right)$ of PAHs

211 in air, as shown in Equation 2. $E_{z}$ was estimated only from measured heat fluxes; 212 the contribution of momentum flux was ignored as the horizontal wind vector 
was small in this study $\left(<1.5 \mathrm{~m} \mathrm{~s}^{-1}\right.$ ) (Kurt-Karakus et al., 2006; Schwarzenbach et

214 al., 2002). Typically, $D_{\mathrm{A}}$ is around $0.05 \mathrm{~cm}^{2} \mathrm{~s}^{-1}$, while in this study $E_{z}$ was in the

215 range of $0.01-0.6 \mathrm{~cm}^{2} \mathrm{~s}^{-1}$ in time-integrated average. Details on estimating the

216 vertical eddy diffusivity and vertical diffusive flux within air phase are provided

217 in the Supporting Information, and the calculated $E_{\text {z, }}$ concentration gradient, and

$218 \quad F_{\text {Dual }}$ values are listed in Table S6-S8.

219

220

$F_{\text {Dual }}=F_{E d d y}+F_{\text {mol. }}=\left(E_{z}+D_{A}\right) \frac{d C}{d H}$

\subsection{Uncertainty analysis on the calculated fluxes.}

223 Error propagation analysis was applied to estimate uncertainty of the air-soil

224 diffusive exchange flux of PAHs $\left(F_{\mathrm{a} / \mathrm{s}}\right)$, errors in PE-air partition coefficients $\left(K_{\mathrm{PE}-}\right.$

225 a), overall mass transfer velocities $\left(v_{a} / s\right)$, concentrations of PAHs in PE strips

226 deployed in air and soil ( $C_{\mathrm{PE}, \mathrm{a}}$ and $\left.C_{\mathrm{PE}, \mathrm{s}}\right)$ were considered, as shown in Equation 3.

227 Five parameters, including vertical eddy diffusivity $\left(E_{\mathrm{z}}\right)$, molecular diffusivity in

228 air $\left(D_{\mathrm{A}}\right)$, height difference $(h)$, concentration of PAHs at different heights $\left(C_{\mathrm{up}}\right.$ and

$229 C_{\text {down }}$ ), were included to estimate uncertainty of vertical diffusive fluxes within

230 the air layer $\left(F_{\text {Dual }}\right)$ in Equation 4.

$232 \frac{\delta F_{a / s}}{F_{a / s}}=\sqrt{\left(\frac{\delta K_{P E-a}}{K_{P E-a}}\right)^{2}+\frac{\left(\delta C_{P E, a}{ }^{2}+\delta C_{P E, s}{ }^{2}\right)}{\left(C_{P E, a}-C_{P E, s}\right)^{2}}+\left(\frac{\delta v_{a / s}}{v_{a / s}}\right)^{2}}$

$233 \frac{\delta F_{\text {Dual }}}{F_{\text {Dual }}}=\sqrt{\frac{\left(\delta E_{Z}{ }^{2}+\delta D_{A}{ }^{2}\right)}{\left(E_{Z}+D_{A}\right)^{2}}+\frac{\left(\delta C_{u p}{ }^{2}+\delta C_{\text {down }}{ }^{2}\right)}{\left(C_{u p}-C_{\text {down }}\right)^{2}}+\left(\frac{\delta h}{h}\right)^{2}}$ 


\section{RESULTS AND DISCUSSION}

\subsection{Vertical concentration profiles of gaseous PAHs in air and transport}

\section{direction of air-soil exchange.}

The vertical concentrations of gaseous PAHs on the air side exhibit distinct concentration gradients in space, and directly reveal the transport direction of PAHs. The vertical concentration distributions of PAHs in air are shown exemplary for campaign ADH04 (2017/6/14 - 2017/6/30) in Figure 1. Gaseous concentrations of phenanthrene (see Figure 1.a) increased with the height, from $16 \mathrm{ng} \mathrm{m}^{-3}$ at $5 \mathrm{~cm}$ to $45 \mathrm{ng} \mathrm{m}^{-3}$ at $50 \mathrm{~cm}$ above ground, where it remained stable (47 - $51 \mathrm{ng} \mathrm{m}^{-3}$ ) within the 1 - $2 \mathrm{~m}$. This indicates gas deposition of phenanthrene from an upper air layer to a lower one close to ground. Turbulence also varied with height, which affected both uptake of PAHs and release of PRCs, and in general, the sampling rate increased with height (see Figure 1.f). Gaseous concentrations of phenanthrene have been corrected based on equilibrium percentage of PRCs observed (see Equations S1-S2). The equivalent gaseous concentrations of phenanthrene in topsoil ranged from $1.62-2.1 \mathrm{ng} \mathrm{m}^{-3}$, which is significantly $(p<0.01)$ lower than in air $\left(16-51 \mathrm{ng} \mathrm{m}^{-3}\right)$. Consequently, transport direction of phenanthrene is confirmed as air-to-soil deposition.

A similar deposition behavior was observed for fluoranthene as shown in Figure 1.b. In contrast, some 4 - 6 rings PAHs showed an unusual volatilization from soil to air, e.g., benzo[b]fluoranthene and benzo[ghi]perylene (Figure 1.c, d, and e); the spatial trend of chrysene in air was unclear, a possible explanation of which is that chrysene reached or approached equilibrium in air-soil exchange process. The downward deposition of lower molecular weight PAHs (especially phenanthrene) indicates a significant emission in Shanghai urban space and on- 
going accumulation of the gaseous PAHs in urban topsoils, whereas the upward

261 volatilization of higher molecular weight PAHs (e.g., 5 - 6 rings PAHs) is different

262 with the general expectation (deposition) and reported observations (Cetin et al., 263 2017a). We ever suspected the LDPE soil samplers and air samplers at lower

264 heights were more vulnerable to be associated with fine soil dust. In the

265 improved experimental process, the LDPE trips were cleaned up by deionized

266 water and swabbed with a hexane-soaked wiper to ensure that only absorbed

267 molecules into the LDPE samplers would be quantified. Interestingly, passive

268 samplers did 'see' the unusual process. The observed volatilization is possibly

269 attributed to local high legacy pollution or a long-term accumulation from dry

270 and wet deposition (ever-increasing soil fugacity is even greater than the air

271 fugacity) in topsoils and the soil acting as a secondary source of the air PAHs.

272 In this study, strong linear correlations were obtained by fitting a relationship

273 of gaseous concentration as a function of log-transformed height. Fitted results

274 (solid line) are presented in Figure $1(R>0.68)$, which were significantly

275 correlated $(p<0.01)$ for most PAHs except chrysene. Kurt-Karakus et al. (2006)

276 reported a volatilization gradient of DDT in a historically treated agricultural soil

277 in Canada and a similar logarithmic function between height and gas

278 concentration. Wang et al. (2017) observed a deposition gradient of

279 organochlorine pesticides in the pasture of the central Tibetan Plateau, but used

280 a power function to fit the relationship. The curve is related to wind speed

281 (Majewski et al., 1990), or to be more precise, to vertical turbulence. The slopes

282 derived here are further used to quantify vertical concentration gradient at

283 different heights and estimate diffusive flux of PAHs within the air layer (see

284 below). Although different functions were used to fit, interestingly, mathematical 
expressions are similar based on derivative of the two functions $(\mathrm{dC} / \mathrm{dH})$ to describe vertical concentration gradient, e.g., $12.97 \mathrm{H}^{-1}$ for phenanthrene in this study and $4.97 \mathrm{H}^{-0.87}$ for DDT from Wang et al (2017).

3.2 Influence of vegetation during the growing season on vertical concentration distribution of gaseous PAHs.

291 Vegetation has been considered as a globally important compartment in

292 scavenging and storing atmospheric pollutants and transferring them into soil 293 through falling litter (Odabasi et al., 2015), or back into the air by re-

294 volatilization (Bao et al., 2016; Terzaghi et al., 2017). Many studies reported 295 urban vegetation as an air pollutant collector based on large scale modeling 296 (Simonich and Hites, 1994; Terzaghi et al., 2017). Furthermore, a lack of 297 experimental investigation has been recognized (Setala et al., 2013). The study 298 here provides an empirical-based evidence on influence of urban vegetation on 299 gaseous PAHs.

300 Vertical distributions of gaseous PAHs before (February), during (March) and 301 after (May - September) the growing season are compared in Figure 2. Gaseous 302 concentrations of phenanthrene, fluoranthene and benzo $[b]$ fluoranthene were 303 normalized to a common condition of $25^{\circ} \mathrm{C}$ and $1 \mathrm{~atm}$ for comparison over time, 304 due to gaseous concentrations of PAHs varying with air temperature and 305 pressure. Field vegetation grew up from $\sim 5 \mathrm{~cm}$ height above ground before the 306 growing season to $\sim 30 \mathrm{~cm}$ height after the growing season. Overall, 307 concentrations of PAHs decreased over time, e.g. phenanthrene from $50 \mathrm{ng} \mathrm{m}^{-3}$ in 308 February to $15 \mathrm{ng} \mathrm{m}^{-3}$ in September. This time trend of gaseous PAHs is similar as 309 air pollution in Shanghai (see Figure S3). Clearly, PAH concentrations are linked 
to overall air quality, however these vertical patterns of PAHs are similar in

311 different campaigns except B2 (in March), especially for phenanthrene at the

312 heights of $10-35 \mathrm{~cm}$ in Figure 2.a. The differences of PAH patterns before, during

313 and after growing seasons are attributed to absorption by vegetation during the

314 growing season. For phenanthrene and fluoranthene deposition in the growing

315 season (B2) resulted in markedly lower concentrations in the vegetation layer

316 than in the upper air layer. However, the adsorption by vegetation was not

317 observed after the growing season.

318 Klingberg et al. (2017) observed substantially lower gaseous PAH levels in

319 parks than adjacent areas near traffic. Ghasemian et al. (2017) reported that the

320 dense canopy improved the near-road air quality. However, the effect remains

321 controversial. Setala's result (2013) suggested a minor capability of urban

322 vegetation to remove air pollutants in northern climates. Moreover, Viippola et al.

323 (2016) and Yli-Pelkonen (2018) reported higher gaseous PAH levels under tree

324 canopies than adjacent open area in southern Finland and northeast China,

325 associating with the trapping of polluted air under canopies and re-volatilization

326 from soil back to the air. Our results support the removal effect of air pollutants

327 by vegetation, but the influence was observable only during the growing season

328 (emergence of new and clean biomass), and the influence faded away after the 329 growing season.

331 3.3. Air-soil diffusive exchange of PAHs.

332 Air-soil diffusive exchange is an interphase transfer process, which is usually

333 characterized by the Whitman two-resistance mass transfer coefficient approach

334 (Schwarzenbach et al., 2002). Quantification of the diffusive flux in an air layer 
335 close to the surface by micrometeorological approach is an alternative method. In

336 this study, the micrometeorological approach focused on an air layer with a

337 specific thickness $(100 \mathrm{~cm})$, in which air turbulence or eddy diffusion as well as

338 random molecular motion together drive pollutant transfer. In the thin layer

339 close to the air-soil interface, eddies tend to be dampened and movement to and

340 from the interface occurs only by molecular diffusion (Mackay, 2001). Both

341 methods were applied to estimate comprehensively on the air-soil diffusive

342 exchange flux in this study.

3.3.1 Estimation of vertical eddy diffusivity within the air layer close to the air-soil surface.

346 Molecular diffusivity is commonly isotropic, while eddy diffusivity in the

347 vertical direction is usually much lower than horizontal diffusion

348 (Schwarzenbach et al., 2002). Vertical eddy diffusion can strongly influence PAH

349 transfer in air-soil exchange process. Vertical eddy diffusivity can be calculated

350 from heat and momentum fluxes, more specifically, from temperature profile and

351 horizontal wind vector, respectively (Kurt-Karakus et al., 2006). Due to a lower

352 wind speed in this case, the vertical eddy diffusivity was linked only to the

353 vertical temperature profile close to the surface.

354 Taking temperature profile within specific three days (including sunny, rainy 355 and cloudy days) for example, the vertical eddy diffusivities $\left(E_{\mathrm{z}}\right)$ at the heights of $3560-5 \mathrm{~cm}, 5-20 \mathrm{~cm}, 20-60 \mathrm{~cm}$, and $60-100 \mathrm{~cm}$ were calculated from the 357 temperature profile mentioned above, and results are presented in Figure 3. First 358 of all, spatial and temporal variations of air temperature were notable. Especially 359 during sunny days, air temperature varied drastically over time due to solar 
radiation, and changed with height above the surface. Moreover, air temperature

361 was much higher than soil temperature during sunny days, while the both

362 temperatures were similar on a rainy day and at nighttime. In addition,

363 vegetation layer was believed to have a significant influence on vertical

364 temperature profile (Daemei et al., 2018). During the deployment period of this

365 study, the height of vegetation layer reached up to $\sim 20 \mathrm{~cm}$ above the surface. It

366 was covered by a dense grass layer, meanwhile the temperature difference

367 between soil and air above vegetation in the sunny day was $>10{ }^{\circ} \mathrm{C}$.

368 Consequently, for monitoring real-time temperature profiles in subsequent work,

369 three temperature sensors were deployed in air above vegetation, vegetation

370 layer and soil surface, respectively.

371 Such temperature profile led inevitably to a great heterogeneity in vertical

372 eddy diffusivity based on the micrometeorological approach, as shown in Figure

373 3.b. When temperature rose constantly in the morning on a sunny day, air masses

374 warmed up, resulting in an updraft and a negative value of $E_{\mathrm{z}}$. After temperature

375 reached a peak value at noon, it decreased continually until night and air masses

376 cooled down causing a downdraft and a positive value of $E_{\text {z. }}$ Therefore, vertical

377 eddy diffusion is a vector with a direction (updraft or downdraft). Figure 3.b

378 demonstrates a remarkable variation of eddy diffusivity over time, in magnitude

379 and direction. We calculated the average time-integrated eddy diffusivities of

380 updraft and downdraft, respectively, similar as the $E_{z}$ values in Figure 4.a and b.

381 Generally speaking, the magnitude of $E_{\mathrm{z}}$ varied with distance to the air-soil

382 surface. The closer to the surface, the smaller $E_{z}$ value was, and even lower than

383 molecular diffusivity of PAHs in air. The vertical pattern of eddy diffusivity is in

384 line with the above statement that eddy diffusion tends to be damped in a thin 
layer close to the surface.

386 As a consequence, solar radiation and vegetation cover control temperature

387 vertical profile and finally influence vertical eddy diffusivity in local micro-

388 environment close to ground.

\subsubsection{Estimation of diffusive flux of gaseous PAHs within the air layer based} on the micrometeorological approach.

Random molecular motion and vertical eddy motion promote vertical

transferring of gaseous PAHs within the air layer close to ground. The diffusive

flux, hence, depends on a vertical gradient of PAH concentration $(d C / d H)$, vertical eddy diffusivity $\left(E_{z}\right)$ and molecular diffusivity $\left(D_{A}\right)$ of PAHs in air. The slopes $\left(d C_{\text {air }} / d \ln (H)\right)$ in Figure 1 and Table S7 were used to calculate the vertical concentration gradient $(d C / d H)$ at different heights above the surface (see Figure 4.a and b). Molecular diffusivity in air is constant at specific condition, e.g. $D_{\mathrm{PhA}, \mathrm{A}}$ $=0.053 \mathrm{~cm}^{2} \mathrm{~s}^{-1}$ for phenanthrene at $25^{\circ} \mathrm{C}$ and $1 \mathrm{~atm}$, while vertical eddy diffusivity in air varies with the height above the air-soil surface, as estimated above and shown in Figure 4.a and b. Additionally, the vertical eddy diffusivity is an instantaneous vector with an upward (negative value) or downward (positive)

403 direction. If the direction of vertical eddy diffusivity was the same as the concentration gradient, gaseous PAHs transfer from high to low concentrations. If not, there is no net PAH deposition during an upward eddy flux. In order to

406 estimate the eddy diffusive flux, we calculated the updraft and downdraft eddy 407 diffusivities in time-integrated average during each sampling campaign, 408 respectively (see Table S6). Eddy diffusive fluxes and molecular diffusive fluxes at 409 the heights $<1 \mathrm{~m}$ above the surface were calculated (see Table S8) and results of 
410 phenanthrene and benzo[b]fluoranthene as examples of deposition and

411 volatilization are shown in Figure 4.

412 Since phenanthrene deposited from air to soil, the positive eddy diffusivities

413 (downward) were used for calculation, as presented in Figure 4.a. The values of

$414 E_{\mathrm{z}}$ close to the surface (height $<0.1 \mathrm{~m}$ ) were lower than molecular diffusivity of

415 phenanthrene in air $\left(0.053 \mathrm{~cm}^{2} \mathrm{~s}^{-1}\right)$. With the increase in height, the $E_{\mathrm{z}}$ values

416 increased up to $\sim 0.61 \mathrm{~cm}^{2} \mathrm{~s}^{-1}$ at the height of $1 \mathrm{~m}, 10$ times greater than the

417 molecular diffusivity in air. As for volatilization of benzo[ $b]$ fluoranthene from soil

418 to air, the negative eddy diffusivities (upward) were used for calculation.

419 Vertical eddy diffusive flux $\left(F_{\text {Eddy }}\right)$ and total diffusive flux $\left(F_{\text {Total }}=F_{\text {Eddy }}+F_{\text {molecular }}\right)$

420 were estimated based on average updraft/downdraft eddy diffusivity, molecular

421 diffusivity and vertical concentration gradient. The results of phenanthrene and

422 benzo $[b]$ fluoranthene are shown in Figure 4.c and d, respectively. In the region

423 close to the air-soil surface (e.g., $<0.1 \mathrm{~m}$ ), molecular diffusion dominated the

424 mass transfer and percentages of eddy flux to total diffusive flux were $<50 \%$ for

425 the two PAHs, as well as uncertainties of the both fluxes were greater than in

426 higher air layer. With increasing distance to the surface, the percentage raised

427 to $>80 \%$ at the height $>0.5 \mathrm{~m}$ (above vegetation layer).

\subsubsection{Estimation of air-soil diffusive exchange flux based on the Mackay's}

430 fugacity approach.

431 To maintain mass balance, the air-soil exchange flux should be equal or similar to

432 the diffusive flux within the air layer. The air-soil exchange fluxes of gaseous

433 PAHs were estimated based on the Mackay's fugacity approach with the Whitman

434 two-resistance model (Mackay, 2001; Schwarzenbach et al., 2002). The exchange 
435 flux is related to the concentration difference between two compartments and 436 overall mass transfer velocity of PAHs in air-soil exchange process. The transfer 437 velocity is linked primarily to PAH molecular diffusivities in the atmosphere, soil 438 air and soil water, the boundary layer thicknesses in atmosphere and soil, soil 439 porosity, volume fraction of air and water in soil, soil temperature and Henry's 440 law constant of PAHs. The air-soil exchange transfer velocities and mass fluxes of 441 PAHs are listed in Table S5, and more calculation details in the SI. The mass 442 transfer velocities of PAHs were estimated as $76-106 \mathrm{~cm}^{-1 a y}{ }^{-1}$ in this study. 443 When calculating the air-soil exchange fluxes based on gradients in air and soil 444 fugacities, Tasdemir et al. (2012) placed air sampler on the roof of a building, 445 Donald et al. (2017) deployed passive sampler at the height of $\sim 1.5 \mathrm{~m}$ above 446 ground, and Wang et al. (2017) chose the air at $0-3 \mathrm{~cm}$ above ground to calculate 447 the flux. Since gaseous PAHs levels tended to stable over $50 \mathrm{~cm}$ above the surface 448 in this study, air concentrations at the heights of $100 \mathrm{~cm}$ and $5 \mathrm{~cm}$ were used to 449 calculate the air-soil exchange fluxes (namely $\mathrm{F}_{100}$ and $\mathrm{F}_{5}$, listed in Tables S5), 450 respectively. Taking data from the sampling campaign ADH04 for example, the 451 air-soil exchange fluxes and diffusive fluxes within the air layer were compared in 452 Table 1. For example, for phenanthrene and fluoranthene, the diffusive fluxes 453 within the air layer were $63.2 \mathrm{ng} \mathrm{m}^{-2}$ day-1 $^{-1}$ and $3.62 \mathrm{ng} \mathrm{m}^{-2}$ day $^{-1}$, respectively and 454 thus slightly greater than the calculated air-soil exchange fluxes (13.3 - $43.6 \mathrm{ng}$ $455 \mathrm{~m}^{-2}$ day $^{-1}$ and $0.19-1.62 \mathrm{ng} \mathrm{m}^{-2}$ day $^{-1}$, respectively). While in the soil-to-air 456 volatilization process (e.g. chrysene, benzo[b]fluoranthene, and 457 benzo[ghi]perylene), the air-soil exchange fluxes were slightly higher than their 458 diffusive fluxes within air layer. But broadly speaking, the two calculated fluxes 459 are comparable based on the two methods, namely the micrometeorological 
approach and the Mackay fugacity approach.

461 In terms of air-soil exchange flux, the values of $F_{100}$ are closer to the diffusive

462 fluxes within air layer in comparison to the $F_{5}$ values, but not indicating that $F_{100}$

463 is recommended. First of all, because of the assumed air boundary thickness of

$4644.75 \mathrm{~mm}$ in the Mackay's fugacity approach (2001), the air concentration should

465 be measured in the air layer as possible as close to the air-soil surface (e.g. $5 \mathrm{~cm})$,

466 and so $F_{5}$ would be recommended rather than $F_{100}$. Second, both of them would

467 be underestimated, but $F_{100}$ is closer to the diffusive flux within air layer due to

468 the greater concentration difference between two compartments. Overall mass

469 transfer velocities $\left(V_{\mathrm{a}} / \mathrm{s}\right)$ of gaseous PAHs in air-soil exchange process were

470 estimated based only on their molecular diffusion here. In fact, day-night change

471 (solar radiation) leads to soil temperature variation, which results in different

472 atmospheric boundary layers and different eddy diffusivities of pollutants in air.

473 The calculated transfer velocity, hence, might be underestimated because of the

474 neglect of eddy diffusion in air.

475 As for air-soil exchange diffusive fluxes in the whole study, observed

476 deposition fluxes were $9.8 \mathrm{ng} \mathrm{m}^{-2}$ day $^{-1}$ for fluorene, $31.4 \mathrm{ng} \mathrm{m}^{-2}$ day $^{-1}$ for

477 phenanthrene, and $2.5 \mathrm{ng} \mathrm{m}^{-2}$ day $^{-1}$ for fluoranthene on average. The other PAHs

478 presented a volatilization flux (e.g. - $0.31 \mathrm{ng} \mathrm{m}^{-2}$ day $^{-1}$ for benzo $[b]$ fluoranthene)

479 or approached equilibrium (e.g. pyrene and perylene, see Table S5).

481 4. CONCLUSIONS

482 In this study, both air-to-soil deposition and soil-to-air volatilization were

483 observed for different PAHs in an urban micro-environment based on their

484 vertical concentration gradients. Concentration-height relationships were 
485 linearized by plotting log-transformed height and gaseous concentrations of

486 PAHs. Influence of vegetation on vertical distribution of PAHs was observable

487 only in the growing season, but insignificant in other seasons. Concentration

488 gradient and micrometeorological condition controlled diffusion of gaseous

489 PAHs. Eddy diffusion dominated the transfer of gaseous PAHs in higher air layer,

490 and was dampened in the layer close to the air-soil surface. Eddy diffusivity was

491 directional and depended mainly on changing vertical profiles of air and soil

492 temperatures. The total diffusive flux within the air layer close to the surface

493 (including vertical eddy diffusive flux and molecular diffusive flux) and air-soil

494 exchange flux based on the Mackay's fugacity approach were comparable to a

495 large extent.

496 This work demonstrated that monitoring vertical concentrations of gaseous

497 PAHs based on LDPE passive sampling technology is vital to assess transport

498 direction and quantify diffusive fluxes in air-soil exchange process. Although

499 there may be differences in air/soil fugacities between passive and active

500 sampling technologies, passive sampling is a logical choice for better observing

501 vertical concentration distribution with a high spatial resolution and without air

502 disturbance of sampling. Due to its low cost, no power requirement, and easy

503 deployment in air and soil compartments, passive sampling provides a useful

504 tool for monitoring air-soil diffusive exchange process, but field correction for

505 non-equilibrium compounds is needed and yet considerable uncertainties in field

506 measurement are unavoidable.

507

508 ASSOCIATED CONTENT

509 Supporting Information 
510 Detailed information on sampling design and flux calculation can be found along

511 with calculated overall mass transfer velocity, eddy diffusivity, and diffusive flux

512 in the estimated site.

513

514 AUTHOR INFORMATION

515 Corresponding Author.

$516 *$ E-mail: liu_ying@tongji.edu.cn

517 Notes

518 The authors declare no competing financial interest.

ACKNOWLEDGEMENTS

521 We acknowledge funding from the National Natural Science Foundation of China

522 (No.: 21876126); the Major Science and Technology Program for Water Pollution

523 Control and Treatment of China (No.: 2018ZX07109-001-004), and the Science

524 and Technology Commission of Shanghai Municipality (Nos.:16ZR1438100 and

525 17DZ1200103).

\section{REFERENCES}

528 Ali, U., Mahmood, A., Syed, J.H., Li, J., Zhang, G., Katsoyiannis, A., Jones, K.C., Malik, R.N., 2015. Assessing the combined influence of TOC and black carbon in soil-air partitioning of PBDEs and DPs from the Indus River Basin, Pakistan. Environmental Pollution 201, 131-140.

Bao, Z., Haberer, C., Maier, U., Beckingham, B., Amos, R.T., Grathwohl, P., 2015. Modeling longterm uptake and re-volatilization of semi-volatile organic compounds (SVOCs) across the soil-atmosphere interface. Science of The Total Environment 538, 789-801.

Bao, Z., Haberer, C.M., Maier, U., Beckingham, B., Amos, R.T., Grathwohl, P., 2016. Modeling short-term concentration fluctuations of semi-volatile pollutants in the soil-plantatmosphere system. Science of The Total Environment 569-570, 159-167.

Booij, K., Smedes, F., 2010. An improved method for estimating in situ sampling rates of nonpolar passive samplers. Environmental Science \& Technology 44, 6789-6794.

Cabrerizo, A., Dachs, J., Barcelo, D., 2009. Development of a Soil Fugacity Sampler for 

Controlled Conditions. Environmental Science \& Technology 43, 8257-8263.

Casal, P., Castro-Jimenez, J., Pizarro, M., Katsoyiannis, A., Dachs, J., 2018. Seasonal soil/snowair exchange of semivolatile organic pollutants at a coastal arctic site (Tromso, 69 degrees N). Science of The Total Environment 636, 1109-1116.

Cetin, B., Ozturk, F., Keles, M., Yurdakul, S., 2017a. PAHs and PCBs in an Eastern Mediterranean megacity, Istanbul: Their spatial and temporal distributions, air-soil exchange and toxicological effects. Environmental Pollution 220, 1322-1332.

Cetin, B., Yurdakul, S., Keles, M., Celik, I., Ozturk, F., Dogan, C., 2017b. Atmospheric concentrations, distributions and air-soil exchange tendencies of PAHs and PCBs in a heavily industrialized area in Kocaeli, Turkey. Chemosphere 183, 69-79.

Cetin, B., Yurdakul, S., Odabasi, M., 2019. Spatio-temporal variations of atmospheric and soil polybrominated diphenyl ethers (PBDEs) in highly industrialized region of Dilovasi. Science of The Total Environment 646, 1164-1171.

Daemei, A.B., Azmoodeh, M., Zamani, Z., Khotbehsara, E.M., 2018. Experimental and simulation studies on the thermal behavior of vertical greenery system for temperature mitigation in urban spaces. Journal of Building Engineering 20, 277-284.

Davie-Martin, C.L., Hageman, K.J., Chin, Y.P., Rouge, V., Fujita, Y., 2015. Influence of Temperature, Relative Humidity, and Soil Properties on the Soil-Air Partitioning of Semivolatile Pesticides: Laboratory Measurements and Predictive Models. Environmental Science \& Technology 49, 10431-10439.

Degrendele, C., Audy, O., Hofman, J., Kucerik, J., Kukucka, P., Mulder, M.D., Pribylova, P., Prokes, R., Sanka, M., Schaumann, G.E., Lammel, G., 2016. Diurnal Variations of Air-Soil Exchange of Semivolatile Organic Compounds (PAHs, PCBs, OCPs, and PBDEs) in a Central European Receptor Area. Environmental Science \& Technology 50, 4278-4288.

Donald, C.E., Anderson, K.A., 2017. Assessing soil-air partitioning of PAHs and PCBs with a new fugacity passive sampler. Science of The Total Environment 596, 293-302.

Dumanoglu, Y., Gaga, E.O., Gungormus, E., Sofuoglu, S.C., Odabasi, M., 2017. Spatial and seasonal variations, sources, air-soil exchange, and carcinogenic risk assessment for PAHs and PCBs in air and soil of Kutahya, Turkey, the province of thermal power plants. Science of The Total Environment 580, 920-935.

Feng, D.L., Liu, Y., Gao, Y., Zhou, J.X., Zheng, L.R., Qiao, G., Ma, L.M., Lin, Z.F., Grathwohl, P., 2017. Atmospheric bulk deposition of polycyclic aromatic hydrocarbons in Shanghai: Temporal and spatial variation, and global comparison. Environmental Pollution 230, 639-647.

Ghasemian, M., Amini, S., Princevac, M., 2017. The influence of roadside solid and vegetation barriers on near-road air quality. Atmospheric Environment 170, 108-117.

Klingberg, J., Broberg, M., Strandberg, B., Thorsson, P., Pleijel, H., 2017. Influence of urban vegetation on air pollution and noise exposure - A case study in Gothenburg, Sweden. Science of The Total Environment 599, 1728-1739.

Koblizkova, M., Růzickova, P., Cupr, P., Komprda, J., Holoubek, I., Klanova, J., 2009. Soil burdens of persistent organic pollutants: their levels, fate, and risks. Part IV. Quantification of volatilization fluxes of organochlorine pesticides and polychlorinated biphenyls from contaminated soil surfaces. Environmental Science \& Technology 43, 3588-3595.

Kurt-Karakus, P.B., Bidleman, T.F., Staebler, R.M., Jones, K.C., 2006. Measurement of DDT fluxes 

from a historically treated agricultural soil in Canada. Environmental Science \& Technology 40, 4578-4585.

Lammel, G., Klanova, J., Eric, L., Ilic, P., Kohoutek, J., Kovacic, I., 2011. Sources of organochlorine pesticides in air in an urban Mediterranean environment: volatilisation from soil. Journal of Environmental Monitoring 13, 3358-3364.

Liu, Y., Gao, Y., Yu, N., Zhang, C., Wang, S., Ma, L., Zhao, J., Lohmann, R., 2015. Particulate matter, gaseous and particulate polycyclic aromatic hydrocarbons (PAHs) in an urban traffic tunnel of China: Emission from on-road vehicles and gas-particle partitioning. Chemosphere 134, 52-59.

Liu, Y., Wang, S., McDonough, C.A., Khairy, M., Muir, D.C., Helm, P.A., Lohmann, R., 2016. Gaseous and Freely-Dissolved PCBs in the Lower Great Lakes Based on Passive Sampling: Spatial Trends and Air-Water Exchange. Environmental Science \& Technology 50, 4932-4939.

Mackay, D., 2001. Multimedia environmental models - The fugacity approach, Second ed. Lewis Publishers, Boca Raton.

Majewski, M.S., Glotfelty, D.E., Paw, K.T., Seiber, J.N., 1990. A Field Comparison of Several Methods for Measuring Pesticide Evaporation Rates from Soil. Environmental Science \& Technology 24, 1490-1497.

McDonough, C.A., Khairy, M.A., Muir, D.C., Lohmann, R., 2014. Significance of population centers as sources of gaseous and dissolved PAHs in the lower Great Lakes. Environmental Science \& Technology 48, 7789-7797.

Odabasi, M., Falay, E.O., Tuna, G., Altiok, H., Kara, M., Dumanoglu, Y., Bayram, A., Tolunay, D., Elbir, T., 2015. Biomonitoring the Spatial and Historical Variations of Persistent Organic Pollutants (POPs) in an Industrial Region. Environmental Science \& Technology 49, 2105 2114.

Pokhrel, B., Gong, P., Wang, X.P., Chen, M.K., Wang, C.F., Gao, S.P., 2018. Distribution, sources, and air-soil exchange of OCPs, PCBs and PAHs in urban soils of Nepal. Chemosphere 200, 532-541.

Qu, C., Albanese, S., Lima, A., Hope, D., Pond, P., Fortelli, A., Romano, N., Cerino, P., Pizzolante, A., De Vivo, B., 2019. The occurrence of OCPs, PCBs, and PAHs in the soil, air, and bulk deposition of the Naples metropolitan area, southern Italy: Implications for sources and environmental processes. Environment International 124, 89-97.

Schwarzenbach, R.P., Gschwend, P.M., Imboden, D.M., 2002. Environmental Organic Chemistry (2nd edition). Wiley Interscience, USA.

Setala, H., Viippola, V., Rantalainen, A.L., Pennanen, A., Yli-Pelkonen, V., 2013. Does urban vegetation mitigate air pollution in northern conditions? Environmental Pollution 183, 104-112.

Simonich, S.L., Hites, R.A., 1994. Importance of Vegetation in Removing Polycyclic AromaticHydrocarbons from the Atmosphere. Nature 370, 49-51.

Tasdemir, Y., Salihoglu, G., Salihoglu, N.K., Birgul, A., 2012. Air-soil exchange of PCBs: seasonal variations in levels and fluxes with influence of equilibrium conditions. Environmental Pollution 169, 90-97.

Terzaghi, E., Morselli, M., Semplice, M., Cerabolini, B.E.L., Jones, K.C., Freppaz, M., Di Guardo, A., 2017. SoilPlusVeg: An integrated air-plant-litter-soil model to predict organic chemical fate and recycling in forests. Science of The Total Environment 595, 169-177. 
Tian, Y., Nie, Z., He, J., Die, Q., Fang, Y., Liu, F., Yang, Y., Gao, X., Huang, Q., 2016. Seasonal variations in concentrations, distributions, and air-soil exchange fluxes of dioxin-like polychlorinated biphenyls in Shanghai, China. Environmental Science and Pollution Research 23, 3376-3384.

Viippola, V., Rantalainen, A.L., Yli-Pelkonen, V., Tervo, P., Setala, H., 2016. Gaseous polycyclic aromatic hydrocarbon concentrations are higher in urban forests than adjacent open areas during summer but not in winter - Exploratory study. Environmental Pollution 208, 233240.

Wang, C.F., Wang, X.P., Ren, J., Gong, P., Yao, T.D., 2017. Using a passive air sampler to monitor air-soil exchange of organochlorine pesticides in the pasture of the central Tibetan Plateau. Science of The Total Environment 580, 958-965.

Wang, Y., Luo, C.L., Wang, S.R., Liu, J.W., Pan, S.H., Li, J., Ming, L.L., Zhang, G., Li, X.D., 2015. Assessment of the Air-Soil Partitioning of Polycyclic Aromatic Hydrocarbons in a Paddy Field Using a Modified Fugacity Sampler. Environmental Science \& Technology 49, 284-291.

Yli-Pelkonen, V., Viippola, V., Rantalainen, A.L., Zheng, J.Q., Setala, H., 2018. The impact of urban trees on concentrations of PAHs and other gaseous air pollutants in Yanji, northeast China. Atmospheric Environment 192, 151-159.

Zhang, Y.Z., Deng, S.X., Liu, Y.A., Shen, G.F., Li, X.Q., Cao, J., Wang, X.L., Reid, B., Tao, S., 2011. A passive air sampler for characterizing the vertical concentration profile of gaseous phase polycyclic aromatic hydrocarbons in near soil surface air. Environmental Pollution 159, 694-699.

Zheng, Q., Nizzetto, L., Liu, X., Borga, K., Starrfelt, J., Li, J., Jiang, Y., Liu, X., Jones, K.C., Zhang, G., 2015. Elevated mobility of persistent organic pollutants in the soil of a tropical rainforest. Environmental Science \& Technology 49, 4302-4309.

Zhu, S.Y., Niu, L.L., Aamir, M., Zhou, Y.T., Xu, C., Liu, W.P., 2017. Spatial and seasonal variations in air-soil exchange, enantiomeric signatures and associated health risks of hexachlorocyclohexanes (HCHs) in a megacity Hangzhou in the Yangtze River Delta region, China. Science of The Total Environment 599, 264-272. 
659 Figure 1. Vertical gas phase concentration profiles of selected PAHs (a - e) and sampling rate (f) at height $5-200 \mathrm{~cm}$ above ground. (Deployment period: June 14 - 30, 2017)

662 Figure 2. Effect of vegetation on the vertical gas phase concentration distribution 663 of (a) phenanthrene, (b) fluoranthene and (c) benzo[b]fluoranthene from topsoil to the air layer close to ground in February (B1), March (B2), May (B3), June (B4), July (B5), and September (B7).

666 Figure 3. Vertical pattern of temperature and eddy diffusivity from topsoil to $1 \mathrm{~m}$ 667 height air.

668

Figure 4. Pattern of vertical eddy diffusivity, concentration gradient, and diffusive 669 fluxes (b) of phenanthrene (PhA) and benzo[b]fluoranthene (BbF).

670

671

672 
673 Table 1. PAH mass flux ${ }^{a}\left(\mathrm{ng} \mathrm{m}^{-2}\right.$ day $\left.^{-1}\right)$ within the air layer close to the ground and in air-soil exchange process.

675

\begin{tabular}{lccc}
\hline \multirow{2}{*}{ PAHs } & Diffusive flux within & \multicolumn{2}{c}{ Air-soil exchange flux } \\
\cline { 3 - 4 } & air layer & $F_{100} \mathrm{~b}$ & $F_{5}$ \\
\hline Phenanthrene & $63.2 \pm 13.6$ & $43.6 \pm 31.6$ & $13.3 \pm 9.5$ \\
Fluoranthene & $3.62 \pm 0.76$ & $1.62 \pm 1.25$ & $0.19 \pm 0.38$ \\
Chrysene & $-0.17 \pm 0.03$ & $-0.39 \pm 0.27$ & $-0.39 \pm 0.27$ \\
Benzo[b]fluoranthene & $-0.03 \pm 0.01$ & $-0.15 \pm 0.10$ & $-0.14 \pm 0.10$ \\
Benzo[ghi]perylene & $-0.04 \pm 0.01$ & $-0.08 \pm 0.05$ & $-0.06 \pm 0.04$ \\
\hline
\end{tabular}

676 a: data from the sampling campaign ADH04. Positive values indicate net deposition, while

677 negative values reflect volatilization from soil to air.

678 b: $F_{100}$ and $F_{5}$ denote fluxes calculated based on the difference of concentrations between the

679 soil surface and the air at a height of $100 \mathrm{~cm}$ above ground, and $5 \mathrm{~cm}$ above the ground.

680

681 

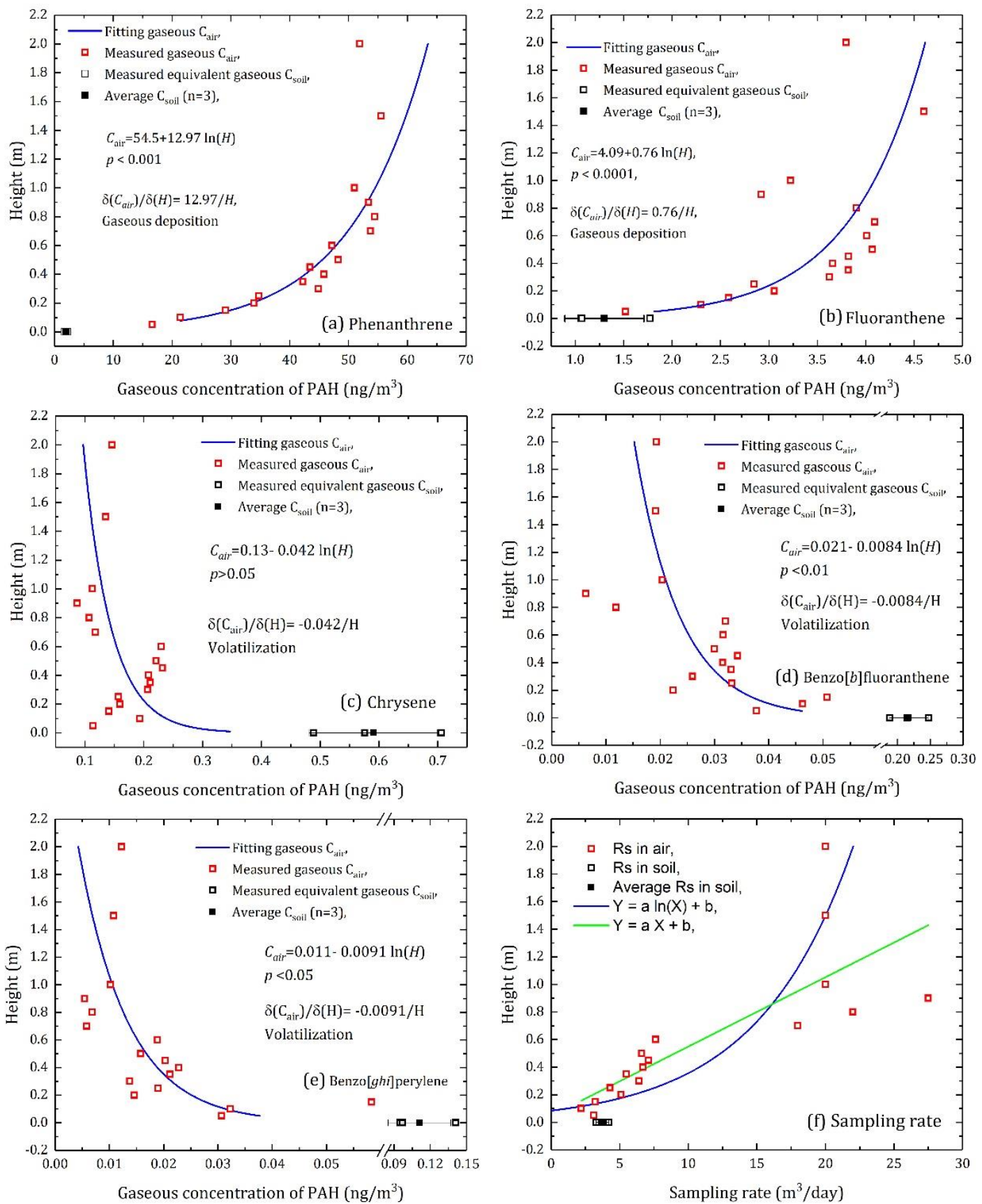

Figure 1. Vertical gas phase concentration profiles of selected PAHs (a - e) and sampling rates (f) at height $5-200 \mathrm{~cm}$ above ground. (Deployment period: June 14 - 30, 2017) 

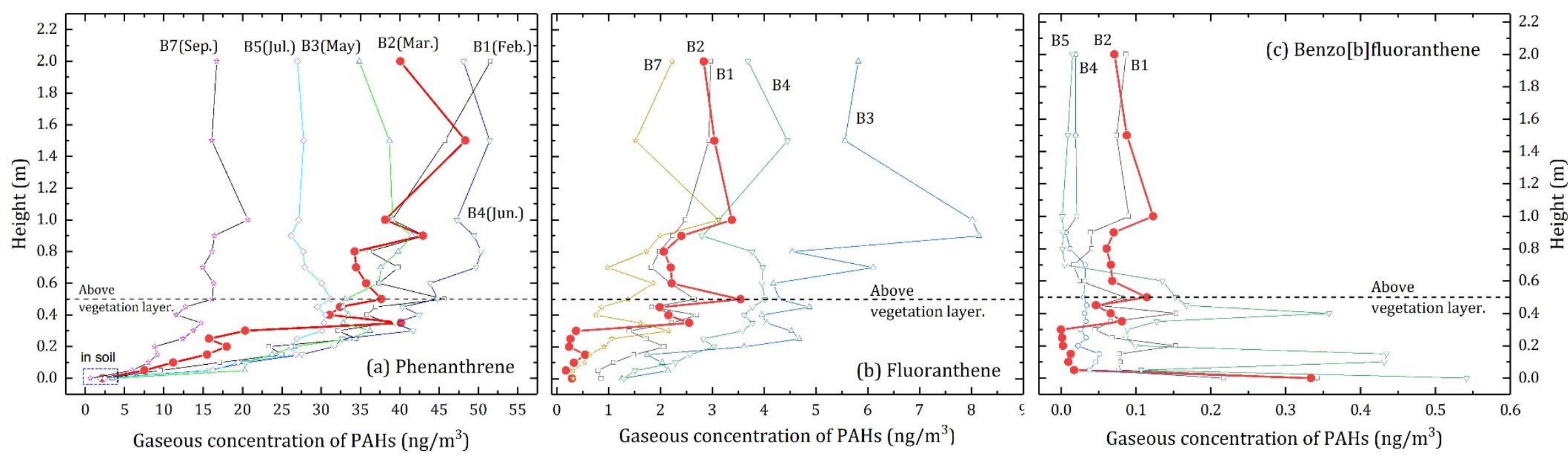

Figure 2. Effect of vegetation on the vertical gas phase concentration distribution of (a) phenanthrene, (b) fluoranthene and (c) benzo $[b]$ fluoranthene from topsoil to the air layer close to ground in February (B1), March (B2), May (B3), June (B4), July (B5), and September (B7). 


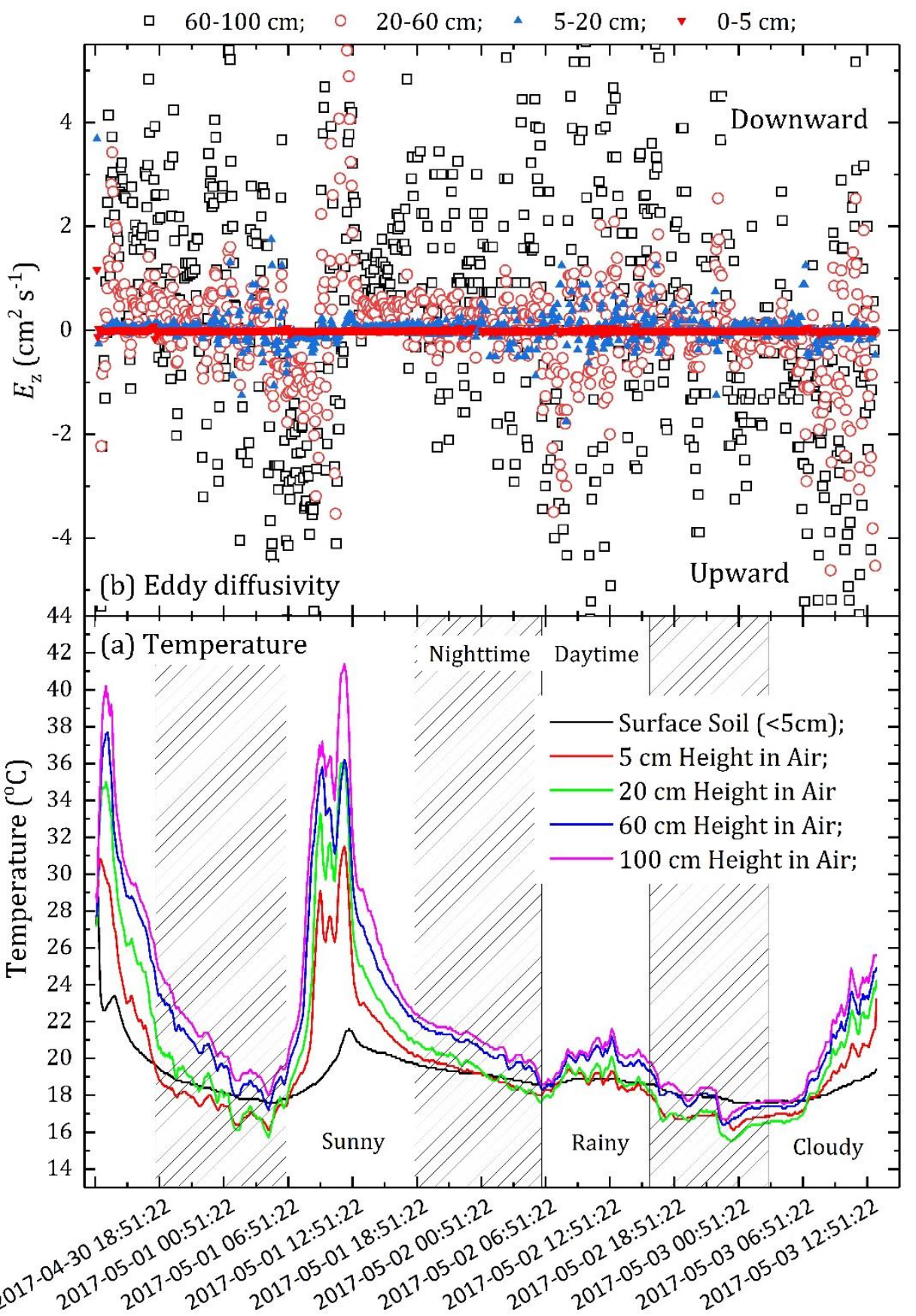

Figure 3. Vertical pattern of temperature and eddy diffusivity from topsoil to $1 \mathrm{~m}$ height air. 
Vertical eddy diffusivity in air $\left(\mathrm{cm}^{2} \mathrm{~s}^{-1}\right) \quad$ Percentage of eddy flux to total diffusive flux(\%)

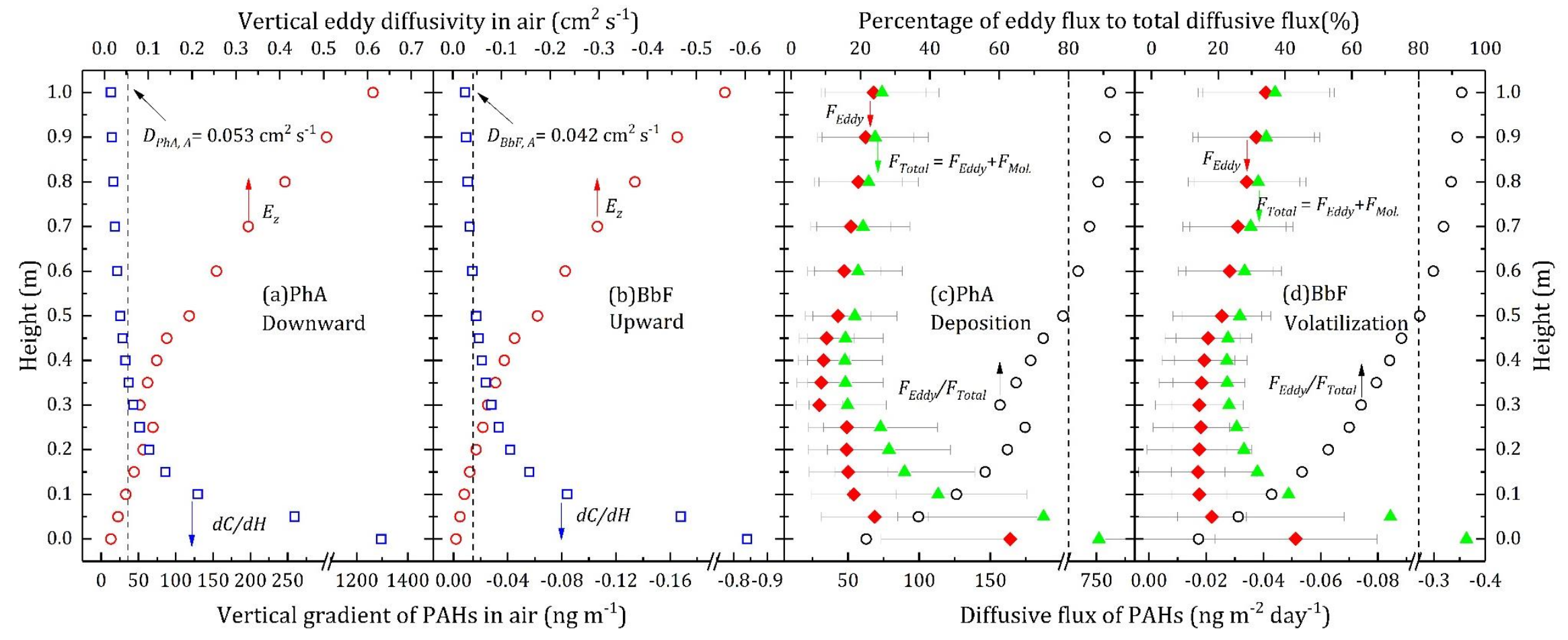

Figure 4. Pattern of vertical eddy diffusivity, concentration gradient, and air diffusive fluxes of phenanthrene $(\mathrm{PhA})$ and benzo[b]fluoranthene $(\mathrm{BbF})$. 
